\title{
Hole Mobilities of 2,7- and 2,2'-Disubstituted 9,9'-Spirobifluorene-Based Triaryldiamines and Their Application as Hole Transport Materials in OLEDs
}

\author{
Yuan-Li Liao, ${ }^{\dagger}$ Wen-Yi Hung, ${ }^{*}{ }^{*}$ Tei-Hung Hou, ${ }^{\ddagger}$ Chi-Yen Lin ${ }^{\dagger}$ and Ken-Tsung Wong ${ }^{*}{ }^{\dagger}$ \\ Department of Chemistry, National Taiwan University, Taipei 106, Taiwan, and Institute of Optoelectronic \\ Sciences, National Taiwan Ocean University, Keelung 202, Taiwan
}

Received August 8, 2007. Revised Manuscript Received September 27, 2007

\begin{abstract}
Hole mobilities of up to $2 \times 10^{-3} \mathrm{~cm}^{2} \mathrm{~V}^{-1} \mathrm{~s}^{-1}$ of 2,7- and 2,2'-disubstituted spirobifluorene-based triaryldiamine derivatives have been measured using time-of-flight (TOF) techniques. Among these derivatives, 27DPSF (possessing diphenylamino groups attached onto the same biphenyl branch of spirobifluorene) and 22DPASF (possessing extended $\pi$-conjugation of the chromophore) exhibited the highest hole mobilities because of their greater intermolecular interactions. The charge transport parameters were extracted, using a Gaussian disorder model (GDM), from detailed temperature- and field-dependent hole mobility measurements. For $2,2^{\prime}$-disubstituted systems possessing different diarylamino groups, the hole mobilities decreased in the order 22DPSF > 22DTSF > 22DBPSF, indicating that spatial hindrance had a crucial effect on the hole transport behavior. To verify these disubstituted spirobifluorene-based amines can be used as HTLs in OLED devices. A standard device was fabricated with the configuration ITO/m-MTDATA $(20 \mathrm{~nm}) /$ triaryldiamine derivative $(40 \mathrm{~nm}) / \mathrm{Alq}_{3}(60 \mathrm{~nm}) / \mathrm{LiF}(0.5 \mathrm{~nm}) / \mathrm{Al}(150 \mathrm{~nm})$, which gave a relatively high current density (ca. $\left.5200 \mathrm{~mA} / \mathrm{cm}^{2}\right)$, impressive maximum brightness $(1.3 \mathrm{X}$ $10^{5} \mathrm{~cd} / \mathrm{m}^{2}$ ), and high external quantum efficiency (1.8\%). The device performances are strongly correlated to the charge transporting behavior of such disubstituted spirobifluorene-based amines.
\end{abstract}

\section{Introduction}

Charge carrier mobility is a key material parameter that influences device performance. Among tested organic materials, triaryldiamines, which sometimes exhibit hole mobilities exceeding $10^{-3} \mathrm{~cm}^{2} \mathrm{~V}^{-1} \mathrm{~s}^{-1}$, have been used widely as hole transporting materials in organic light-emitting diodes (OLED) and in xerography. ${ }^{1}$ These compounds, however, often possess low glass transition temperatures $\left(T_{\mathrm{g}}\right)$, i.e., poor morphological stability, which results in their low reliability when used in optoelectronic devices. As a consequence, many structural modifications have been made in attempts to develop new amorphous triarylamines possessing high morphological stability. ${ }^{2}$ One of the most promising approaches is the introduction of spiro-type linkages, covalently bridged orthogonal structural configurations that can reduce crystallization tendencies efficiently, ${ }^{3}$ leading to triarylamine

*Corresponding authors. E-mail: kenwong@ntu.edu.tw; wenhung@ mail.ntou.edu.tw.

National Taiwan University.

National Taiwan Ocean University.

(1) (a) Strohriegl, P.; Grazulevicius, J. V. Adv. Mater. 2002, 14, 1439 (b) Fong, H. H.; Lun, K. C.; So, S. K. Chem. Phys. Lett. 2002, 407, 353.

(2) (a) Shirota, Y. J. Mater. Chem. 2000, 10, 1. (b) Wong, K.-T.; Wang, Z.-J.; Chien, Y.-Y.; Wang, C.-L. Org. Lett. 2001, 3, 2285. (c) Koene, B. E.; Loy, D. E.; Thompson, M. E. Chem. Mater. 1998, 10, 2235. (d) Hreha, R. D.; George, C. P.; Haldi, A.; Domercq, B.; Malagoli, M.; Barlow, S.; Brédas, J.-L.; Kippelen, B.; Marder, S. R. Adv. Funct. Mater. 2003, 13, 967.

(3) (a) Salbeck, J.; Yu, N.; Bauer, J.; Weissörtel, F.; Begsten, H. Synth. Met. 1997, 91, 209. (b) Salbeck, J.; Weissörtel, F.; Bauer, J. Macromol. Symp. 1997, 125, 121. (c) Bach, U.; Lupo, D.; Compte, P.; Moser, J. E.; Weissörtel, F.; Salbeck, J.; Spreitzer, H.; Grätzel, M. Nature (London) 1998, 395, 583. derivatives exhibiting higher values of $T_{\mathrm{g}}$. For example, the Salbeck group established a tetrasubstituted spirobifluorenebased amine, 2,2',7,7'-tetrakis(diphenylamino)-9, 9' -spirobifluorene (spiro-TAD), that exhibits improved morphological stability (value of $T_{\mathrm{g}}$ up to $133^{\circ} \mathrm{C}$ ). ${ }^{4}$ More importantly, the three-dimensional structural feature of spiro-TAD allows it to exhibit remarkable hole transport properties $\left(\mu_{\mathrm{h}}=\mathrm{ca} .10^{-4}\right.$ $\left.\mathrm{cm}^{2} \mathrm{~V}^{-1} \mathrm{~s}^{-1}\right){ }^{5}$ Nevertheless, the structural parameters that influence the hole transport properties of spirobifluorenebased triaryldiamines have not been reported previously. Herein, we present a systematic study on the hole transport properties of 2,7- and 2,2'-disubstituted spirobifluorene-based triaryldiamines and compare them to those of the parent nonspiro-linked model compound, $N, N, N^{\prime}, N^{\prime}$-tetraphenylbenzidine (TPB), to provide further understanding of the relationship between the structures and hole mobilities of spirobifluorene-based triaryldiamine derivatives.

\section{Experimental Section}

1. Synthesis. 22DPSF: $2,2^{\prime}$-Diamino- $9,9^{\prime}$-spirobifluorene (3.46 $\mathrm{g}, 10 \mathrm{mmol})$, iodobenzene $(6.8 \mathrm{~mL}, 60 \mathrm{mmol}), \mathrm{Pd}(\mathrm{OAc})_{2}(0.112 \mathrm{~g}$, $0.5 \mathrm{mmol})$, sodium tert-butoxide $(14.4 \mathrm{~g}, 150 \mathrm{mmol})$, and tri-tertbutylphosphine $(1.0 \mathrm{mmol})$ were mixed in a flask containing toluene

(4) (a) Steuber, F.; Staudigel, J.; Stössel, M.; Simmerer, J.; Winnacker, A.; Spreitzer, H.; Weissörtel, F.; Salbeck, J. Adv. Mater. 2000, 12, 130. (b) Saragi, T. P. I.; Fuhrmann-Lieker, T.; Salbeck, J. Adv. Funct. Mater. 2006, 16, 966. (c) Saragi, T. P. I.; Fuhrmann-Lieker, T.; Salbeck, J. Synth. Met. 2005, 148, 267.

(5) (a) Bach, U.; Cloedt, K. D.; Spreitzer, H.; Grätzel, M. Adv. Mater. 2000, 12, 1060. (b) Poplavskyy, D.; Nelson, J. J. Appl. Phys. 2003, $93,341$. 
$(50 \mathrm{~mL})$. The mixture was heated under reflux overnight under argon. After addition of water $(20 \mathrm{~mL})$ into the mixture, the solution was extracted twice with chloroform. The combined organic extracts were dried $\left(\mathrm{MgSO}_{4}\right)$ and concentrated. Column chromatography on silica gel (hexane/chloroform, 4:1) afforded 22DPSF as a white

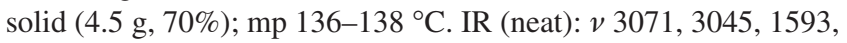
1493, 1440, $1295 \mathrm{~cm}^{-1} .{ }^{1} \mathrm{H}$ NMR $\left(\mathrm{CDCl}_{3}, 400 \mathrm{MHz}\right): \delta 7.66(\mathrm{~d}$, $J=7.5 \mathrm{~Hz}, 2 \mathrm{H}), 7.61(\mathrm{~d}, J=8.1 \mathrm{~Hz}, 2 \mathrm{H}), 7.29(\mathrm{t}, J=7.5 \mathrm{~Hz}$, 2H), 7.18-7.14 (m, 4H), $7.06(\mathrm{t}, J=7.5 \mathrm{~Hz}, 2 \mathrm{H}), 7.00-6.92(\mathrm{~m}$, $7 \mathrm{H}), 6.74(\mathrm{~d}, J=7.5 \mathrm{~Hz}, 2 \mathrm{H}), 6.65(\mathrm{~s}, 2 \mathrm{H}) .{ }^{13} \mathrm{C} \mathrm{NMR}\left(\mathrm{CDCl}_{3}\right.$, $100 \mathrm{MHz}$ ): $\delta 149.9,148.7,147.6,147.3,141.2,136.8,129.0,127.5$, $126.9,124.4,123.7,123.6,122.4,120.7,119.9,119.4,65.7 . \mathrm{MS}$ (m/z, FAB) 650 (30). Anal. Calcd: C, 90.43; H, 5.27; N, 4.30. Found: C, 90.45; H, 5.37; N, 4.37.

22DTSF: A procedure similar to that described above for the synthesis of 22DPSF was applied. Column chromatography on silica gel (hexane/chloroform, 5:1) afforded the product as a white solid (5.9 g, 72\%); mp 259-260 ${ }^{\circ} \mathrm{C}$. IR (neat): $v$ 3032, 2925, 1606, $1500,1447,1314,1295 \mathrm{~cm}^{-1} .{ }^{1} \mathrm{H}$ NMR $\left(d_{6}\right.$-DMSO, $\left.400 \mathrm{MHz}\right): \delta$ $7.77-7.73(\mathrm{~m}, 4 \mathrm{H}), 7.29(\mathrm{t}, J=7.4 \mathrm{~Hz}, 2 \mathrm{H}), 7.06-6.99(\mathrm{~m}, 10 \mathrm{H})$, $6.83(\mathrm{~d}, J=8.3 \mathrm{~Hz}, 2 \mathrm{H}), 6.76(\mathrm{~d}, J=7.5 \mathrm{~Hz}, 8 \mathrm{H}), 6.58(\mathrm{~d}, J=$ $7.5 \mathrm{~Hz}, 2 \mathrm{H}), 6.25$ (s, 2H), $2.20(\mathrm{~s}, 12 \mathrm{H}) .{ }^{13} \mathrm{C} \mathrm{NMR}\left(\mathrm{CDCl}_{3}, 100\right.$ $\mathrm{MHz}): \delta 149.8,148.9,147.7,145.3,141.3,136.1,129.6,127.4$, $126.6,123.7,123.6,123.4,120.5,119.2,118.9,65.7,20.7 . \mathrm{MS}$ (m/z, FAB) 706 (30). Anal. Calcd: C, 90.05; H, 5.99; N, 3.96. Found: C, 90.22; H, 5.73; N, 3.74.

22DBPSF: A procedure similar to that described above for the synthesis of 22DPSF was applied. Column chromatography on silica gel (hexane/chloroform, 6:1) afforded the product as a white solid (5.3 g, 60\%); $\mathrm{mp} 286-287^{\circ} \mathrm{C}$. IR (neat): $v$ 3032, 2925, 1606, 1500, 1447, 1314, $1295 \mathrm{~cm}^{-1} .{ }^{1} \mathrm{H}$ NMR $\left(\mathrm{CDCl}_{3}, 400 \mathrm{MHz}\right): \delta$ $7.64(\mathrm{~d}, J=7.6 \mathrm{~Hz}, 2 \mathrm{H}), 7.58(\mathrm{~d}, J=8.2 \mathrm{~Hz}, 2 \mathrm{H}), 7.28(\mathrm{t}, J=7.5$ $\mathrm{Hz}, 2 \mathrm{H}), 7.16(\mathrm{~d}, J=8.7 \mathrm{~Hz}, 8 \mathrm{H}), 7.05(\mathrm{t}, J=7.5 \mathrm{~Hz}, 2 \mathrm{H}), 6.96$ $(\mathrm{d}, J=8.2 \mathrm{~Hz}, 2 \mathrm{H}), 6.90(\mathrm{~d}, J=8.7 \mathrm{~Hz}, 8 \mathrm{H}), 6.74(\mathrm{~d}, J=7.6 \mathrm{~Hz}$, 2H), 6.66 (s, 2H), 1.28 (s, 18H). ${ }^{13} \mathrm{C} \mathrm{NMR}\left(\mathrm{CDCl}_{3}, 100 \mathrm{MHz}\right): \delta$ 149.9, 148.8, 147.6, 145.0, 141.4, 136.3, 127.4, 126.7, 125.7, 123.9, $123.7,122.9,120.4,119.6,119.2,65.7,34.1,31.4$. MS ( $m / z$, FAB $)$ 875 (95). Anal. Calcd: C, 89.20; H, 7.60; N, 3.20. Found: C, 89.31; H, 7.68; N, 3.04 .

22DPASF: $2,2^{\prime}$-Diiodo-9, $9^{\prime}$-spirobifluorene $(2.84 \mathrm{~g}, 5 \mathrm{mmol})$, 4-(diphenylamino)phenylboronic acid (4.34 g, $15 \mathrm{mmol}), \mathrm{Pd}\left(\mathrm{PPh}_{3}\right)_{4}$ (0.289 g, $0.25 \mathrm{mmol}), 2 \mathrm{M} \mathrm{K}_{2} \mathrm{CO}_{3}$ (aq) $(25 \mathrm{~mL})$, and tri-tertbutylphosphine $(0.5 \mathrm{mmol})$ were mixed in a flask containing toluene $(50 \mathrm{~mL})$. The mixture was heated under reflux for $72 \mathrm{~h}$, and then the solution was extracted twice with chloroform. The combined organic extracts were dried $\left(\mathrm{MgSO}_{4}\right)$ and concentrated through rotary evaporation. Column chromatography on silica gel (hexane/ chloroform, 3:1) afforded the product as a white solid (2.4 g, 60\%); mp 202-204 ${ }^{\circ} \mathrm{C}$. IR (neat): $v$ 3071, 3045, 1600, 1507, 1487, 1460 $\mathrm{cm}^{-1} .{ }^{1} \mathrm{H} \mathrm{NMR}\left(\mathrm{CDCl}_{3}, 400 \mathrm{MHz}\right): \delta 7.88(\mathrm{~d}, J=8.0 \mathrm{~Hz}, 2 \mathrm{H})$, $7.85(\mathrm{~d}, J=7.6 \mathrm{~Hz}, 2 \mathrm{H}), 7.59$ (d, $J=7.8 \mathrm{~Hz}, 2 \mathrm{H}), 7.37(\mathrm{t}, J=7.5$ $\mathrm{Hz}, 2 \mathrm{H}), 7.30$ (d, $J=8.5 \mathrm{~Hz}, 4 \mathrm{H}), 7.23-6.95$ (m, 28H), 6.77 (d, $J$ $=7.6 \mathrm{~Hz}, 2 \mathrm{H}) .{ }^{13} \mathrm{C} \mathrm{NMR}\left(\mathrm{CDCl}_{3}, 100 \mathrm{MHz}\right): \delta 149.5,149.0,147.5$, 147.0, 134.9, 129.2, 127.7, 126.3, 124.2, 124.0, 123.8, 122.8, 122.2, 120.3, 119.9, 66.1. MS (m/z, FAB) 803 (100). HRMS $\left(\mathrm{M}^{+}, \mathrm{FAB}\right)$ Calcd: $\mathrm{C}_{61} \mathrm{H}_{42} \mathrm{~N}_{2}$ 802.3348. Found: 802.3350.

2. Device Fabrication and Measurement. All chemicals were purified through vacuum sublimation prior to use. The OLEDs were fabricated by vacuum deposition of the materials at $10^{-6}$ Torr onto ITO-coated glass substrates having a sheet resistance of $15 \Omega$ square $^{-1}$. The ITO surface was cleaned through ultrasonication sequentially with acetone, methanol, and deionized water, and then it was treated with UV ozone. The deposition rate of each organic material was ca. $1-2 \AA \mathrm{s}^{-1}$. Subsequently, LiF was deposited at
$0.1 \AA \mathrm{s}^{-1}$ and then capped with $\mathrm{Al}$ (ca. $5 \AA \mathrm{s}^{-1}$ ) by shadow masking without breaking the vacuum. The current-voltage-brightness $(I-V-L)$ characteristics of the devices were measured simultaneously using a Keithley 6430 source meter and a Keithley 6487 picoammeter equipped with a calibration $\mathrm{Si}$ photodiode. EL spectra were measured using an Ocean Optics spectrometer.

3. TOF Mobility Measurement. Samples were prepared through vacuum deposition using a structure glass/Ag (30 nm)/organic material $(2-3 \mu \mathrm{m}) / \mathrm{Ag}(150 \mathrm{~nm})$ having an active area of $2 \mathrm{~mm} \times$ $2 \mathrm{~mm}$. For the TOF measurements, the samples were mounted in a cryostat under vacuum (ca. $10^{-3}$ Torr), and the temperature was controlled using a PID thermocontroller. A sheet of charge carriers in the organic layer was generated by radiating a short excitation pulse (nitrogen-tunable dye laser) through the semitransparent Ag electrode. Under an applied dc voltage, these charge carriers sweep over the organic sample toward the counter electrode (Ag) and discharge to result in a transient photocurrent. When the carriers reached the counter electrode, the current dropped to zero; the time at which this event occurred corresponded to the transit time of the carriers. The photocurrent signal was detected using a digital storage oscilloscope. Selected carriers (holes or electrons) drifted across the sample upon switching the polarity of the applied bias. The carrier mobility $(\mu)$ was calculated from the transit time $\left(t_{\mathrm{T}}\right)$, the sample thickness $(d)$, and the applied voltage $(V)$ using the expression $\mu=d^{2} / t_{\mathrm{T}} V$.

\section{Results and Discussion}

1. Synthesis and Characterization. Scheme 1 displays the structures of the materials used in this study. Tetraphenylbenzidine (TPB) ${ }^{6}$ and 2,7-bis(diphenylamino)-9,9'-spirobifluorene (27DPSF) ${ }^{7}$ were synthesized according to published procedures. ${ }^{8} 2,2^{\prime}$-Bis(diphenylamino)-9, $9^{\prime}$-spirobifluorene $(\text { 22DPSF })^{9}$ has been reported to function as an effective hole transporting material when incorporated into a highly efficient blue electrophosphorescent device. ${ }^{10}$ 27DPSF and 22DPSF are geometric isomers whose diphenylamino substituents are attached at different positions on the spirobifluorene core.

Using the same synthetic protocol as that described for 22DPSF, we synthesized several derivatives possessing various terminal substituents (Scheme 2). Coupling 2,2'diamino-9, $9^{\prime}$-spirobifluorene with excess amounts of aryl halides through Pd-catalyzed aminations gave 2,2'-bis(ditolylamino)-9, $9^{\prime}$-spirobifluorene (22DTSF) and 2,2'-bis[di(4-tert-butylphenyl)amino]-9,9'-spirobifluorene (22DBPSF) in 72 and $60 \%$ yields, respectively.

Embedding an additional $p$-phenylene ring between the diphenylamino groups and the central spirobifluorene extended the $\pi$-conjugation length, giving rise to $2,2^{\prime}$-bis[(diphenylaniline)-4-yl]-9, $9^{\prime}$-spirobifluorene (22DPASF). 22DPASF was obtained in $60 \%$ yield through Suzuki

(6) Naito, K.; Miura, A. J. Phys. Chem. 1993, 97, 6240.

(7) Chien, Y.-Y.; Wong, K.-T.; Chou, P.-T.; Cheng, Y.-M. Chem. Commun. 2002, 23, 2874.

(8) (a) Low, P. J.; Paterson, M. A. J.; Yufit, D. S.; Howard, J. A. K.; Cherryman, J. C.; Tackley, D. R.; Brook, R.; Brown, B. J. Mater. Chem. 2005, 15, 2304. (b) Wong, K.-T.; Ku, S.-Y.; Cheng, Y.-M.; Lin, X.-Y.; Hung, Y.-Y.; Pu, S.-C.; Chou, P.-T.; Lee, G.-H.; Peng, S.-M. J. Org. Chem. 2006, 71, 456.

(9) Chiang, C.-L.; Shu, C.-F.; Chen, C.-T. Org. Lett. 2005, 7, 3717.

(10) M.-H.; Tsai, H.-W.; Lin, H.-C.; Su, C.-C.; Wu, F.-C.; Fang, Y.-L.; Liao, K.-T.; Wong, C.-I.; Wu, Adv. Mater. 2006, 18, 1216. 
Scheme 1. Chemical Structures of Materials Used in This Study

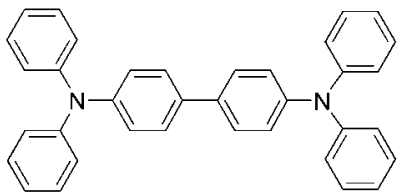

TPB

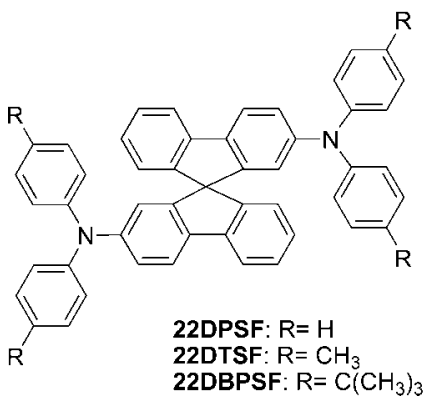

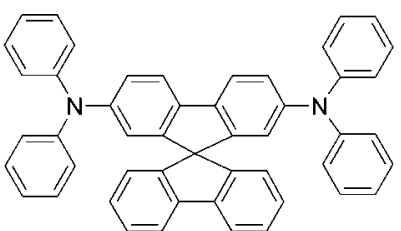

27DPSF

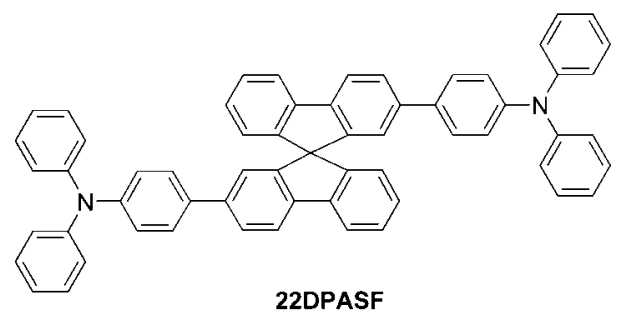

Scheme 2. Syntheses of 2,7- and 2,2'-Disubstituted Spirobifluorene-Based Triaryldiamine Derivatives
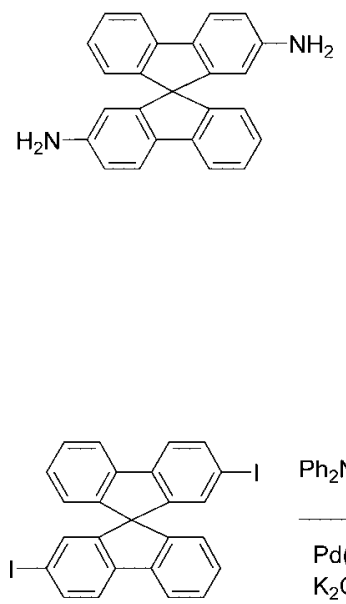

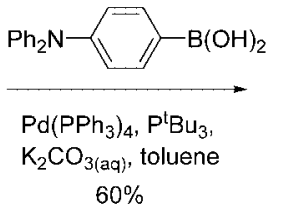

$60 \%$

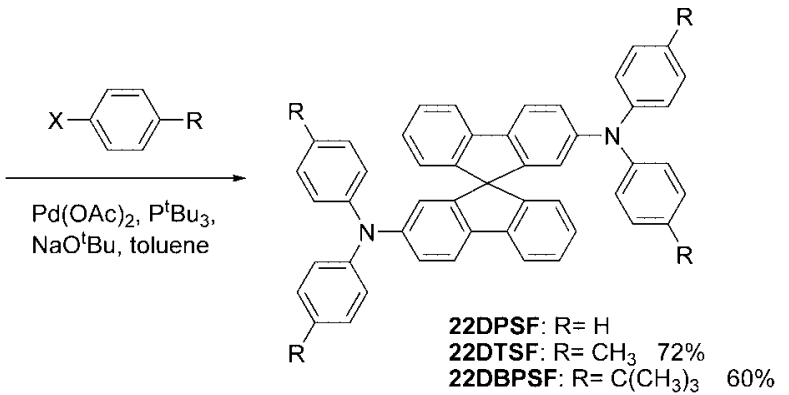

Table 1. Physical Properties of Spirobifluorene-Based Triaryldiamine Derivatives

\begin{tabular}{lcccc}
\hline compound & $T_{\mathrm{g}}\left({ }^{\circ} \mathrm{C}\right)$ & $T_{\mathrm{d}}\left({ }^{\circ} \mathrm{C}\right)$ & $\begin{array}{c}\text { abs } \lambda_{\max }(\mathrm{nm}) \\
\text { solution/film }\end{array}$ & $\begin{array}{c}\text { PL } \lambda_{\max }(\mathrm{nm}) \\
\text { solution/film }\end{array}$ \\
\hline 27DPSF & 112 & 329 & $353 / 382$ & $401 / 409,429$ \\
22DPSF & 115 & 370 & $352 / 356$ & $394 / 407$ \\
22DTSF & 119 & 373 & $353 / 357$ & $406 / 414$ \\
22DBPSF & 146 & 381 & $360 / 357$ & $406 / 407$ \\
22DPASF & 156 & 437 & $352 / 354$ & $416 / 416,426$
\end{tabular}

coupling of 2,2'-diiodo-9, $9^{\prime}$-spirobifluorene ${ }^{11}$ with 4 -(diphenylamino)phenylboronic acid in the presence of a catalytic amount of $\mathrm{Pd}\left(\mathrm{PPh}_{3}\right)_{4}$ and tri-tert-butylphosphine (Scheme 2).

We used differential scanning calorimetry (DSC) and thermogravimetric analysis (TGA) to study the morphological and thermal properties, respectively, of the spiro-linked triaryldiamine derivatives; Table 1 summarizes the results.

All of the compounds exhibited distinct glass transition temperatures $\left(T_{\mathrm{g}}\right)$, ranging from 112 to $156^{\circ} \mathrm{C}$. TGA analysis

(11) Wong, K.-T.; Liao, Y.-L.; Peng, Y.-C.; Wang, C.-C.; Lin, S.-Y.; Yang, C.-H.; Teng, S.-M.; Lee, G.-G.; Peng, S.-M. Cryst. Growth Des. 2005, 5,667 .

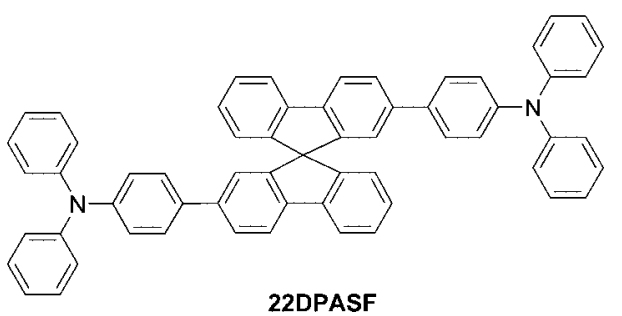

also indicated that these compounds were thermally stable, with decomposition temperatures $\left(T_{\mathrm{d}}\right)$, relative to $5 \%$ weight loss, ranging from 329 to $437^{\circ} \mathrm{C}$. The increased morphological stability, which allowed high-quality amorphous thin films to be formed through thermal evaporation, can be attributed partially to the increased molecular weights, ${ }^{12}$ e.g., cf. the values of $T_{\mathrm{g}}$ of 22DPSF, 22DTSF, and 22DBPSF. Table 1 summarizes the electronic absorption and photoluminescence (PL) spectra of these spirobifluorene-cored compounds in chloroform solution and as solid films. The spectral features were influenced only slightly by changes in the nature of the substituents attached to either the same or different biphenyl branches of the spirobifluorene core. Among these derivatives, 22DPASF exhibited limited red shift in film emission wavelength as compared to those of others due to the extended $\pi$-conjugation. We estimated the $\pi-\pi^{*}$ band gaps $\left(\Delta E_{\mathrm{g}}\right.$; Table 2$)$ from the lowest energy absorption edges in the UV-vis absorption spectra.

(12) Katsuma, K.; Shirota, Y. Adv. Mater. 1998, 10, 223. 
Table 2. Physical Properties of Spirobifluorene-Based Triaryldiamine Derivatives

\begin{tabular}{lcccc}
\hline compound & $E_{1 / 2} \mathrm{oX}^{\mathrm{V}}(\mathrm{V})^{a}$ & $\mathrm{HOMO}(\mathrm{eV})^{b}$ & $\mathrm{LUMO}(\mathrm{eV})$ & $\Delta E_{\mathrm{g}}(\mathrm{eV})$ \\
\hline 27DPSF & $0.70,1.02$ & -5.26 & -2.13 & 3.13 \\
22DPSF & $0.87,0.94$ & -5.43 & -2.26 & 3.17 \\
22DTSF & $0.76,0.87$ & -5.32 & -2.18 & 3.14 \\
22DBPSF & $0.76,0.85$ & -5.32 & -2.16 & 3.16 \\
22DPASF & 0.95 & -5.51 & -2.35 & 3.16
\end{tabular}

${ }^{a}$ Oxidation $\mathrm{CV}$ was performed in $\mathrm{CH}_{2} \mathrm{Cl}_{2}$ with $0.1 \mathrm{M} n \mathrm{Bu}_{4} \mathrm{NPF}_{6}$ as a supporting electrolyte. Scan rate: $100 \mathrm{mV} / \mathrm{s} .{ }^{b} \mathrm{HOMO}$ energy level calculated using a linear correlation with a known compound $(\alpha-\mathrm{NPB}$; $\mathrm{HOMO}=$ ca. $5.3 \mathrm{eV}$ ), which exhibits a value of $E_{1 / 2}{ }^{\mathrm{OX}}$ of $0.74 \mathrm{~V}$, as measured under the same conditions.

Using cyclic voltammetry (CV), we detected two reversible oxidation potentials for the triaryldiamine derivatives in which the diarylamino substituents were attached directly to the spirobifluorene core (27DPSF, 22DPSF, 22DTSF, and 22DBPSF), whereas only one reversible oxidation occurred at a higher potential $(0.95 \mathrm{~V})$ for compound 22DPASF (Table 2). All of the oxidations could be attributed to the removal of electrons from the diarylamino centers. The low first oxidation potential of the 2,7-disubstituted compound (27DPSF), relative to those of the $2,2^{\prime}$-disubstituted species (22DPSF, 22DTSF, and 22DBPSF), was due to significant Coulombic repulsion between the two nitrogen atoms attached to the same biphenyl branch of the spirobifluorene. The significant difference $(E=0.32 \mathrm{~V})$ between the potentials of the first and second oxidations of 27DPSF indicates that efficient resonance delocalization of the radical cation occurred within the chromophore. Compared with that of 27DPSF, the differences in the oxidation potentials observed for the 2,2'-disubstituted compounds (22DPSF, 22DTSF, and 22DBPSF) were less pronounced. We believe that the two diarylamino groups of 22DPSF, 22DTSF, and 22DBPSF were sequentially oxidized, with Coulombic repulsion from the first delocalized radical cation resulting in oxidation of the second diarylamino group occurring at a higher potential. The slightly higher oxidation potential of 22DPSF, relative to those of 22DTSF and 22DBPSF, indicates that the electronic nature of the substituents on the diarylamino group also plays a role in affecting the oxidation potential. We estimated the highest occupied molecular orbital (HOMO) energy levels from the oxidation potentials of each compound in relation to the redox couple of $N, N^{\prime}-$ bis-(1-naphthyl)- $N, N^{\prime}$-diphenyl-1, $1^{\prime}$-biphenyl-4,4'-diamine ( $\alpha$ NPB), ${ }^{13}$ which exhibited its first reversible oxidation at 0.74 $\mathrm{V}$ in dichloromethane; the corresponding lowest unoccupied molecular orbital (LUMO) energy levels were deduced by taking the difference between the HOMO energy level and the band gap. The results are also summarized in Table 2, which indicates that altering the position and electronic nature of the substituents allows slight modulation of the HOMO and LUMO energy levels.

2. Hole Mobility Measurements. We used time-of-flight (TOF) techniques ${ }^{14}$ to measure the charge carrier mobilities of the non-spiro model compound (TPB) and the spirobifluorene-based triaryldiamines with different substituents.

(13) D'Andrade, B. W.; Datta, S.; Forrest, S. R.; Djurovich, P.; Polikarpov, E.; Thompson, M. E. Org. Electron. 2005, 6, 11.

(14) Borsenberger, P. M.; Weiss, D. S. Organic Photoreceptors for Imaging Systems; Marcel Dekker: New York, 1993.
Figure 1a-f displays typical room-temperature TOF transients of holes for TPB and the spirobifluorene-based triaryldiamine derivatives under an applied field.

For TPB, 22DPASF, and 27DPSF, we observe that the transient photocurrent exhibited a distinct plateau — a signature of nondispersive charge transport behavior-implying that the carriers moved with constant velocity across the organic films. The nondispersive transport behavior was, however, not clear for TPB relative to that of its counterpart 27DPSF; this behavior could possibly be ascribed to the unstable morphology of the TPB film because of its low value of $T_{\mathrm{g}}$ and, consequently, to its high tendency for crystallization. In contrast, for the triaryldiamines with two diarylamino substituents attached to different biphenyl branches of the spirobifluorene, such as 22DPSF, 22DTSF, and 22DBPSF, we observed photocurrents that did not display any distinct constant current plateau; instead, the current decayed significantly, resulting in dispersive charge transport, suggesting that the charge carriers were trapped and could not attain dynamic equilibrium while migrating across the sample. The transit times $\left(t_{\mathrm{T}}\right)$ were obtained from the intersection point of two asymptotes in the doublelogarithmic representations (insets of Figure 1a-f). The mobilities of the charges were calculated using the relation $\mu=d^{2} / V t_{\mathrm{T}}$, where $d$ is the organic film thickness, $V$ is the applied voltage, and $t_{\mathrm{T}}$ is the transit time. Figure 2 summarizes the hole mobilities of the disubstituted spirobifluorene-based triaryldiamine derivatives and model compound TPB at room temperature against the square root of the applied electric field. The linear correlation follows the universal Poole-Frenkel relationship, $\mu \propto \exp \left(\beta E^{1 / 2}\right)$, where $\beta$ is the Poole-Frenkel factor and $E$ is the electric field. ${ }^{15}$ The hole mobilities were in the range from $2 \times 10^{-5}$ to $2 \times$ $10^{-3} \mathrm{~cm}^{2} \mathrm{~V}^{-1} \mathrm{~s}^{-1}$ for fields varying from $10^{5}$ to $6.4 \times 10^{5}$ $\mathrm{V} \mathrm{cm}^{-1}$. In contrast to the case of holes, the TOF transients of these samples for electrons exhibited strong dispersive photocurrents.

Carrier transport in an amorphous organic solid that can be commonly described by Marcus theory ${ }^{16}$ is generally associated with charge carriers hopping along the channel of localized hopping sites. The intermolecular hopping rate from an initial state to a final state is strongly dependent on the intermolecular distance and the degree of overlapping of wave functions between adjacent molecules. Among our series of triaryldiamine analogues, TPB, which features no spatially hindering moieties to block intermolecular interactions, exhibits the highest hole mobility (ca. $2 \times 10^{-3} \mathrm{~cm}^{2} \mathrm{~V}^{-1} \mathrm{~s}^{-1}$ ) relative to those of other spirobifluorene-based triaryldiamines. The excellent hole mobility is comparable to those of well-known biphenylene diamine derivatives such as $\alpha$-NPB. ${ }^{1}$ Unfortunately, the favorable intermolecular interactions for hole migration led to TPB having a low thin film stability, i.e., a high trend toward crystallization; this inferior property limits the long-term application of TPB as a stable hole transporting material. The orthogonal structural configu-

(15) Borsenberger, P. M.; Pautmeier, L.; Bässler, H. J. Chem. Phys. 1991, 94, 5447.

(16) Marcus, R. A. Rev. Mod. Phys. 1993, 65, 599. 

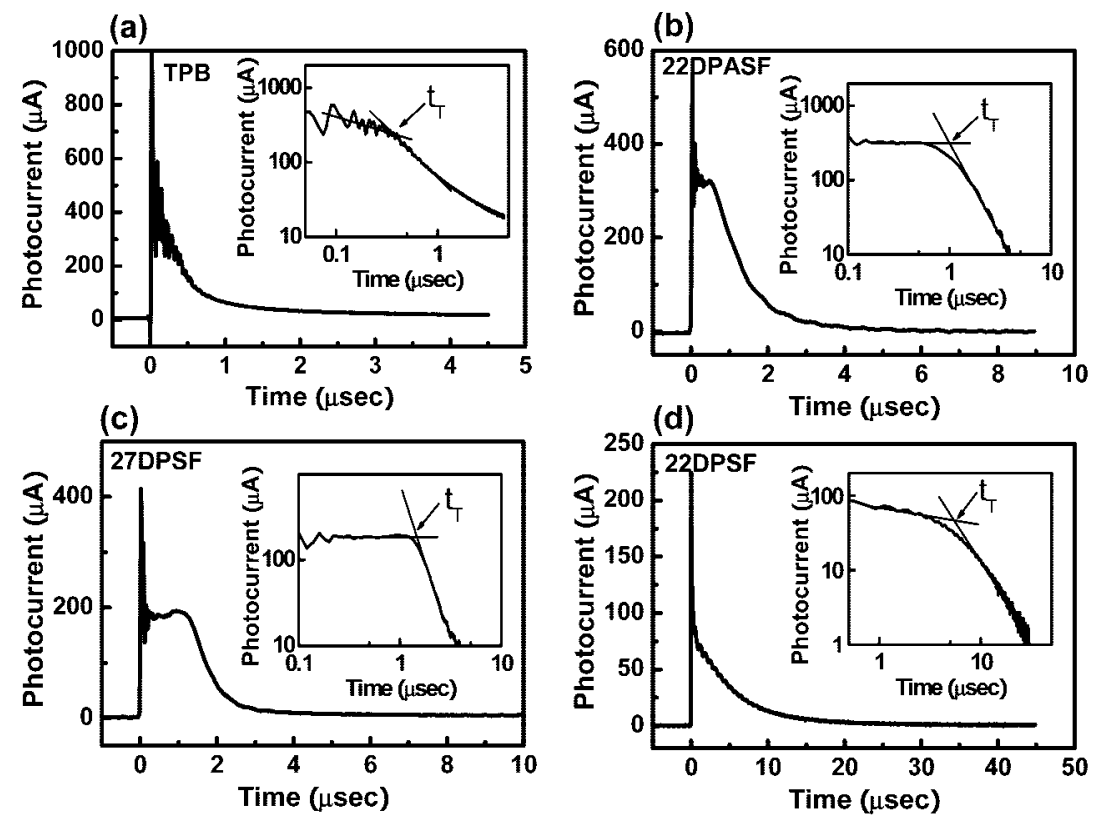

(e)
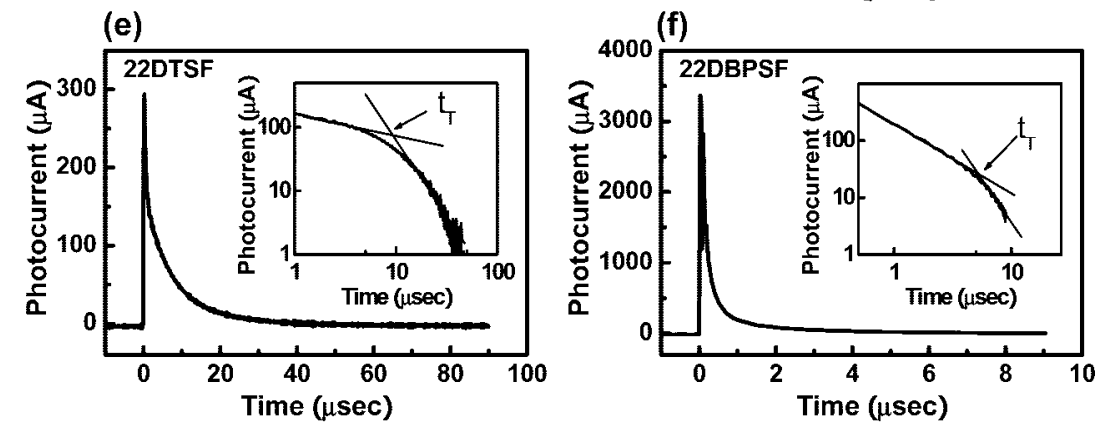

Figure 1. Representative TOF transients for holes at room temperature: (a) TPB at $E=3.3 \times 10^{5} \mathrm{~V} \mathrm{~cm}^{-1}$, (b) $22 \mathrm{DPASF}$ at $E=2.5 \times \mathrm{V} \mathrm{cm}^{-1}$, (c) $27 \mathrm{DPSF}$ at $E=3.1 \times 10^{5} \mathrm{~V} \mathrm{~cm}^{-1}$, (d) 22DPSF at $E=2.5 \times 10^{5} \mathrm{~V} \mathrm{~cm}^{-1}$, (e) 22DTSF at $E=3.3 \times 10^{5} \mathrm{~V} \mathrm{~cm}^{-1}$, (f) 22DBPSF at $E=6 \times 10^{5} \mathrm{~V} \mathrm{~cm}{ }^{-1}$. Insets to (a)-(f) are double-logarithmic plots of the data in (a)-(f), respectively.

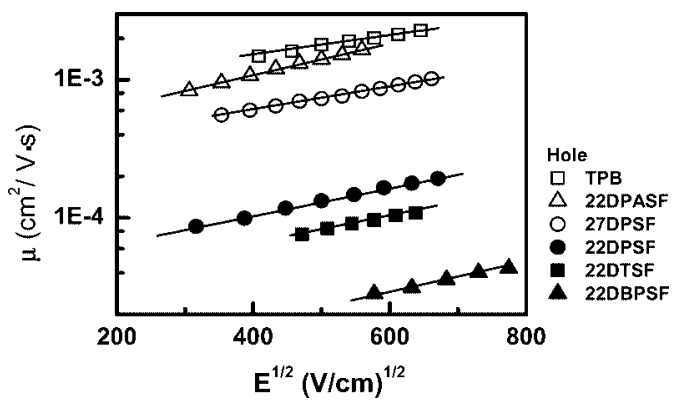

Figure 2. Hole mobilities plotted with respect to $E^{1 / 2}$ for triaryldiamine derivatives (the solid line is a fit of the Poole-Frenkel form).

ration of spirobifluorene provides sufficient steric hindrance to suppress intermolecular interactions, rendering the resultant triaryldiamines with relatively high morphological stabilities - an important issue for their stability in organic thin film devices. The improved morphological stability of 27DPSF indicates the presence of relatively weak intermolecular interactions, which were compensated by a slightly lower hole mobility relative to that of TPB. 22DPSF is the isomer of 27DPSF in which the two diphenylamino groups are attached individually to two different biphenyl branches of the spirobifluorene core. The observed hole mobility of 22DPSF was significantly lower than that of 27DPSF, which we ascribe to the perpendicular arrangement of the two active sites for hole migrating in 22DPSF. The orthogonal configuration leads to a larger spatial hindrance between neighboring 22DPSF molecules and, subsequently, increases the carrier hopping distance. The steric effects toward retarding hole transportation are even more evident after introducing more bulky terminal substituents, as indicated by the hole mobilities decreasing in the order 22DPSF > 22DTSF > 22DBPSF. The terminating units attached to the diphenylamino groups act as extra and effective roles of spatial hindrance, not only to suppress the tendency to crystallize (leading to higher values of $T_{\mathrm{g}}$ ) but also to retard charge carrier transportation in an efficient manner. ${ }^{17}$ Thus, smaller sized substituents reduce the carrier hopping distance between the adjacent molecules, leading to improved mobility. Despite the perpendicular configuration of its two triarylamine groups through the spiro linkage, it is interesting that the hole mobility of 22DPASF, which featured embedded $p$-phenylene rings between the diphenylamino groups and the spiro core, was almost 1 order of magnitude higher than that of 22DPSF and comparable to that of its 2,7-disubstituted counterpart, 27DPSF. The increased hole mobility observed in 22DPASF is likely

(17) Fong, H. H.; So, S. K.; Sham, W. Y.; Lo, C. F.; Wu, Y. S.; Chen, C. H. Chem. Phys. 2004, 298, 119. 
(a)

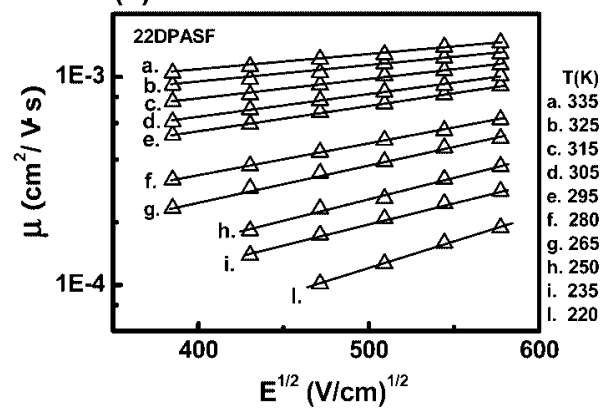

(b)

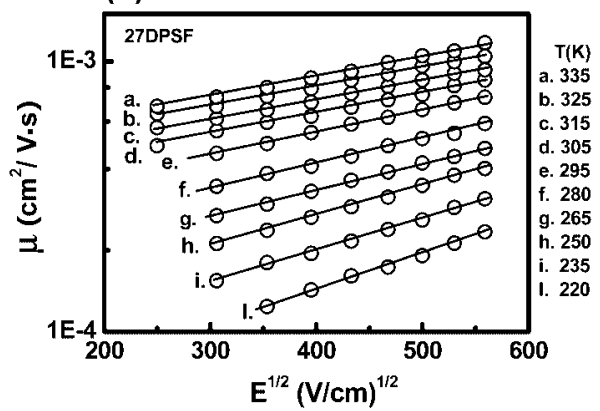

Figure 3. TOF hole mobilities plotted as functions of the electric field strength and temperature for (a) 22DPASF and (b) 27DPSF.

(a)

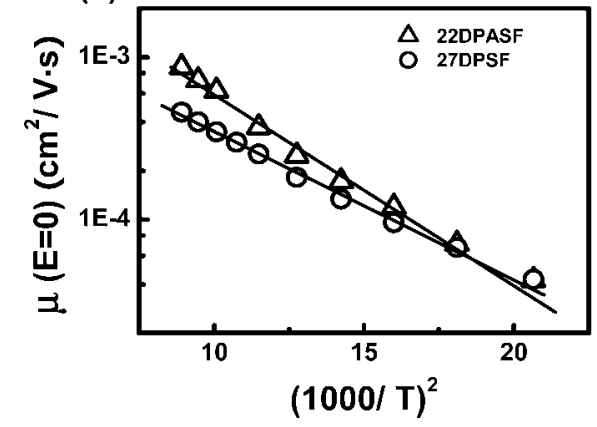

(b)

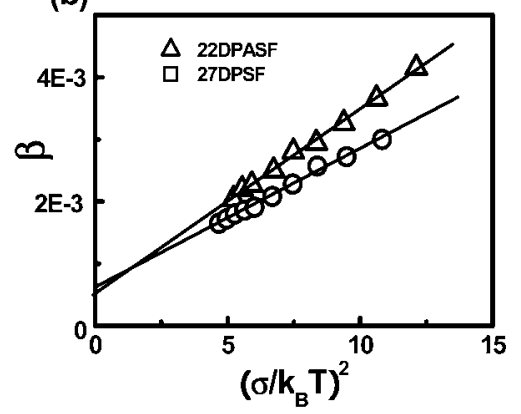

Figure 4. (a) Temperature dependence of hole mobility at zero electric field yields parameters $\mu_{0}$ and $\sigma$. (b) Plot of $\beta$ vs $\left(\sigma / k_{\mathrm{B}} T\right)^{2}$ yields parameters $\Sigma$ and $C$.

to be related to the extended $\pi$-conjugation length, which may enhance the capability of effective interchromophore interaction between neighboring molecules and, thus, decrease the hopping distance. The orthogonal molecular configuration of 22DPASF also imparts spatial hindrance, which subsequently leads to a stronger electric-fielddependent hole mobility, as indicated by a larger value of $\beta$ (the slope in Figure 2).

3. Temperature and Field Dependence of Hole Mobility. To extract the charge transport parameters and to obtain further insight into the transport properties, we performed nondispersive hole mobility measurements of 22DPASF and 27DPSF over a wide range of electric field strengths and temperatures; Figure $3 \mathrm{a}, \mathrm{b}$ displays the results.

As expected, the hole mobility followed the Poole-Frenkel law at each of the temperatures studied, with the parameter $\beta$ increasing upon decreasing the temperature. Such temperature and field dependence has been observed for many amorphous organic materials; it is usually analyzed using the Gaussian disorder model (GDM) proposed by Bässler and co-workers. ${ }^{18}$ Within this model, charge carriers move by hopping through a variety of localized sites with Gaussian distributed energetic and positional disorder. The energetic disorder, described by the parameter $\sigma$, is the energetic width of the density of states arising from the fluctuations of energy levels. The positional disorder is defined by the parameter $\Sigma$, which is attributed to the fluctuations of intermolecular distances or the mutual orientation of neighboring sites. For Monte Carlo simulations based on these assumptions, the

(18) Bässler, H. Phys. Status Solidi B 1993, 175, 15. field and temperature dependences of the mobility are described by the empirical formula

$$
\begin{aligned}
\mu(E, T) & =\mu_{0} \exp \left[-\left(\frac{2 \sigma}{3 k_{\mathrm{B}} T}\right)^{2}\right] \exp C\left[\left(\sigma / k_{\mathrm{B}} T\right)^{2}-\Sigma^{2}\right] \sqrt{E}, \\
\Sigma & \geq 1 \\
& =\mu_{0} \exp \left[-\left(\frac{2 \sigma}{3 k_{\mathrm{B}} T}\right)^{2}\right] \exp C\left[\left(\sigma / k_{\mathrm{B}} T\right)^{2}-2.25\right] \sqrt{E},
\end{aligned}
$$

where $\mu_{0}$ is the prefactor mobility, $k_{\mathrm{B}}$ is Boltzmann's constant, $\sigma$ and $\Sigma$ are parameters representing the degrees of energetic and positional disorder, respectively, and $C$ is an empirical constant. The field- and temperature-dependent mobility data presented in Figure 3 were applied to determine the values of $\mu_{0}, \sigma, \Sigma$, and $C$ using the above equation. From the fit of the zero-field mobilities $\mu(0, T)$, Figure 4 a displays a plot of $\ln \mu(0, T)$ vs $1 / T^{2}$. The prefactor mobility $\mu_{0}$ and the energetic disorder parameter $\sigma$ were extracted from the intercept and slope, respectively. Furthermore, extrapolation of the slope of the plot of $\beta(T)$ vs $\left(\sigma / k_{\mathrm{B}} T\right)^{2}$ provides access to the values of $C$ and the positional disorder $\Sigma$, as indicated in Figure $4 \mathrm{~b}$, where $\beta=C\left[\left(\sigma / k_{\mathrm{B}} T\right)^{2}-\Sigma\right]{ }^{19}$

Table 3 summarizes the hole transport parameters derived from fitting the experimental data to the GDM. The values of the prefactor mobility $\mu_{0}$ (i.e., the intrinsic intermolecular charge-transfer characteristic) of 22DPASF and 27DPSF were $9.4 \times 10^{-3}$ and $3.5 \times 10^{-3} \mathrm{~cm}^{2} \mathrm{~V}^{-1} \mathrm{~s}^{-1}$, respectively.

(19) (a) Inigo, A. R.; Chang, C. C.; Fann, W.; White, J. D.; Huang, Y.-S.; Jeng, U.-S.; Sheu, H. S.; Peng, K.-Y.; Chen, S.-A. Adv. Mater. 2005, 17, 1835. (b) Laquai, F.; Wegner, G.; Im, C.; Bässler, H.; Büsing, A.; Falcou, A.; Heun, S. J. Appl. Phys. 2006, 99, 023712. (c) Laquai, F.; Wegner, G.; Im, C.; Bässler, H.; Heun, S. J. Appl. Phys. 2006, 99 , 033710 . 
Table 3. Parameters Derived from TOF Mobility Data Using GDM

\begin{tabular}{lcccc}
\hline & $\mu_{0}\left[\mathrm{~cm}^{2} \mathrm{~V}^{-1} \mathrm{~s}^{-1}\right]$ & $\sigma[\mathrm{eV}]$ & $\Sigma$ & $C\left(\times 10^{-4}\right)$ \\
\hline 22DPASF & $9.4 \times 10^{-3}$ & $6.77 \times 10^{-2}$ & $<1.5$ & 3 \\
27DPSF & $3.5 \times 10^{-3}$ & $6.20 \times 10^{-2}$ & $<1.5$ & 2.4
\end{tabular}

Table 4. EL Characteristics of Devices Incorporating Spirobifluorene-Core Triaryldiamine Derivatives as HTLs

\begin{tabular}{|c|c|c|c|c|c|}
\hline HTL & $\begin{array}{c}\text { turn-on } \\
\text { voltage }[\mathrm{V}]\end{array}$ & $\begin{array}{c}L_{\max } \\
{\left[\mathrm{cd} \mathrm{m}^{-2}\right]}\end{array}$ & $\begin{array}{c}I_{\max } \\
{\left[\mathrm{mA} \mathrm{cm}^{-2}\right]}\end{array}$ & $\begin{array}{c}\eta_{\text {ext,max }} \\
{\left[\%, \mathrm{~cd} \mathrm{~A}^{-1}\right]}\end{array}$ & $\begin{array}{c}\eta_{\mathrm{p}, \max } \\
{\left[1 \mathrm{~m} \mathrm{~W}^{-1}\right]}\end{array}$ \\
\hline TPB & 2 & $\begin{array}{r}122000 \\
(16 \mathrm{~V})\end{array}$ & 3700 & $1.85,5.6$ & 3.1 \\
\hline 27DPSF & 2 & $\begin{array}{r}130000 \\
(15 \mathrm{~V})\end{array}$ & 5200 & $1.60,4.9$ & 2.7 \\
\hline 22DPSF & 3 & $\begin{array}{l}86000 \\
(17 \mathrm{~V})\end{array}$ & 2100 & $1.64,5.2$ & 1.4 \\
\hline 22DTSF & 2 & $\begin{array}{l}120000 \\
(16.5 \mathrm{~V})\end{array}$ & 4400 & $1.80,5.6$ & 1.9 \\
\hline 22DBPSF & 2 & $\begin{array}{l}120000 \\
(17.5 \mathrm{~V})\end{array}$ & 3500 & $1.58,5.5$ & 1.5 \\
\hline 22DPASF & 3 & $\begin{array}{l}64000 \\
(18 \mathrm{~V})\end{array}$ & 2500 & $1.40,4.3$ & 1.5 \\
\hline
\end{tabular}

Similar values have been observed previously from studies of related triarylamine compounds. ${ }^{4 \mathrm{~b}}$ Again, the larger value of $\mu_{0}$ of 22DPASF could be explained qualitatively by considering its extended $\pi$-conjugation length, which leads to a higher probability of the wave functions of neighboring molecules overlapping. The influence of the energetic disorder parameter $\sigma$ might be due to the dipole moment of the molecule. ${ }^{20}$ The orthogonally configured 22DPASF possesses a larger permanent dipole moment than does the symmetric 27DPSF. As the dipolar strength of a molecule increases, fluctuations are generated in the electrostatic potential between a charge and the surrounding molecules to spread the energetic disorder. Therefore, the energetic disorder $\sigma$ of 22DPASF $(67.7 \mathrm{meV})$ is higher than that of 27DPSF $(62 \mathrm{meV})$.

4. Electroluminescence. To assess the feasibility of using spirobifluorene-based triaryldiamine derivatives in electroluminescence (EL) applications, we employed them as hole transport layers in OLED devices having the configuration indium tin oxide (ITO) $/ 4,4^{\prime}, 4^{\prime \prime}$-tris(3-methylphenylamino) triphenylamine ( $m$-MTDATA, $20 \mathrm{~nm}$ )/triaryldiamine derivatives $(40 \mathrm{~nm}) /$ tris (8-hydroxyquinoline)aluminum $\left(\mathrm{Alq}_{3}, 60\right.$ $\mathrm{nm}) / \mathrm{LiF}(0.5 \mathrm{~nm}) / \mathrm{Al}(150 \mathrm{~nm})$. In this device structure, the thin $m$-MTDATA film was used as a hole-injecting buffer layer ${ }^{21}$ and $\mathrm{Alq}_{3}$ as both an ETL and an emission layer. ${ }^{22}$ Table 4 summarizes the EL characteristics of the OLEDs incorporating spirobifluorene-based triaryldiamine derivatives as HTLs.

All of the devices exhibited high EL performance, apart from that incorporating 22DPASF, which exhibited a relatively low EL efficiency with detection of a portion of the emission of 22DPASF, was indicated in Figure 5a. This behavior arose presumably because of the large barrier for holes at the $m$-MTDATA-22DPASF interface, resulting in a low degree of hole transport into the $\mathrm{Alq}_{3}$ layer, and few

(20) (a) Deckmann, A.; Bässler, H.; Borsenberger, P. M. J. Chem. Phys. 1993, 99, 8136. (b) Heun, S.; Borsenberger, P. M. Chem. Phys. 1995, $200,245$.

(21) Shirota, Y.; Kuwabara, Y.; Inada, H.; Wakimoto, T.; Nakada, H.; Yonemoto, Y.; Kawami, S.; Imai, K. Appl. Phys. Lett. 1994, 65, 807.

(22) Tang, C. W.; Slyke, S. A. V. Appl. Phys. Lett. 1987, 51, 913. electrons leaking from the $\mathrm{Alq}_{3}$ layer to recombine with holes in the 22DPASF layer. The turn-on voltage and current density of a device are dependent on the HOMO energy level and the hole mobility of the employed HTL material. ${ }^{23}$ The turn-on voltages of the devices incorporating 22DPASF and 22DPSF (which have lower HOMO energy levels) as HTLs were slightly higher (ca. $3 \mathrm{~V}$ ) than those of the others. In contrast, 27DPSF, 22DTSF, and 22DBPSF have comparable HOMO energy levels, and hence, their devices' performances can be ascribed to their hole transport properties. From this viewpoint, the current densities of the devices under the same potential decreased in the order 27DPSF > 22DTSF > 22DBPSF (Figure 5c), which agrees well with the order of the TOF hole mobility measurements. 27DPSF, with its slightly higher HOMO and hole mobility, can endure a relatively high current density (ca. $5200 \mathrm{~mA} \mathrm{~cm}^{-2}$ ), and consequently, it provides an impressive maximum brightness of nearly $1.3 \times 10^{5} \mathrm{~cd} \mathrm{~m}^{-1}$ at ca. $15 \mathrm{~V}$. In this case, however, the hole mobility of 27DPSF is much larger than the electron mobility of $\mathrm{Alq}_{3}\left(1.4 \times 10^{-6} \mathrm{~cm}^{2} \mathrm{~V}^{-1} \mathrm{~s}^{-124}\right)$, which leads to an imbalance of holes and electrons in the emitting zone. In contrast, the device incorporating 22DTSF as the HTL exhibited high external quantum efficiency (1.8\%; Figure 5d). These results provide clear experimental evidence that, in comparison with the model compound TPB, triaryldiamines constructed around spirobifluorene linkages possess high thermal stability and hole transport mobilities and molecular energy levels that can be tailored to prepare OLED devices that display remarkable EL characteristics.

\section{Conclusion}

We have performed a systematic study of the physical properties and hole transport-structure relationships of 2,7and $2,2^{\prime}$-disubstituted spirobifluorene-based triaryldiamine derivatives, relative to those of the model compound TPB. The introduction of a spirobifluorene unit as a central core is highly beneficial, providing higher thermal and morphological stability to the resultant triaryldiamines. The physical properties can be tailored through modification of the substitution pattern of the spirobifluorene core and the nature of the aryl groups on the diarylamino substituents. From TOF measurements, we observed both nondispersive (TPB, 22DPASF, and 27DPSF) and dispersive (2DPSF, 22DTSF, and 22DBPAS) hole mobilities (up to $2 \times 10^{-3} \mathrm{~cm}^{2} \mathrm{~V}^{-1} \mathrm{~s}^{-1}$ ). The good hole transporting properties of TPB are retained after incorporating the diphenylamino groups onto the same biphenyl branch of the spirobifluorene (27DPSF) or by extending the $\pi$-conjugation of the chromophore (22DPASF). In addition, spatial hindrance affects the hole transport behavior critically, as indicated by the hole mobilities decreasing in the order 22DPSF > 22DTSF > 22DBPSF. Using

(23) Giebeler, C.; Antoniadis, H.; Bradley, D. D. C.; Shirota, Y. J. Appl. Phys. 1999, 85, 608.

(24) Kepler, R. G.; Beeson, P. M.; Jacobs, S. J.; Anderson, R. A.; Sinclair, M. B.; Valencia, V. S.; Cahill, P. A. Appl. Phys. Lett. 1995, 66, 3618. 
(a)
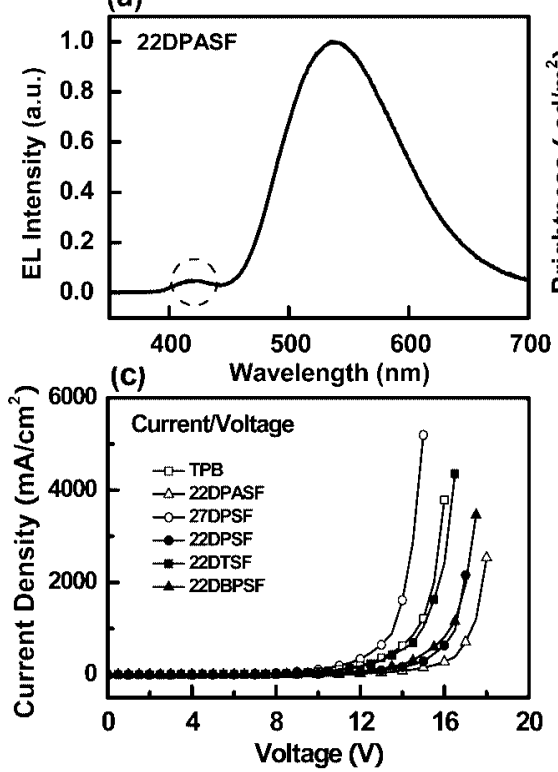

(b)
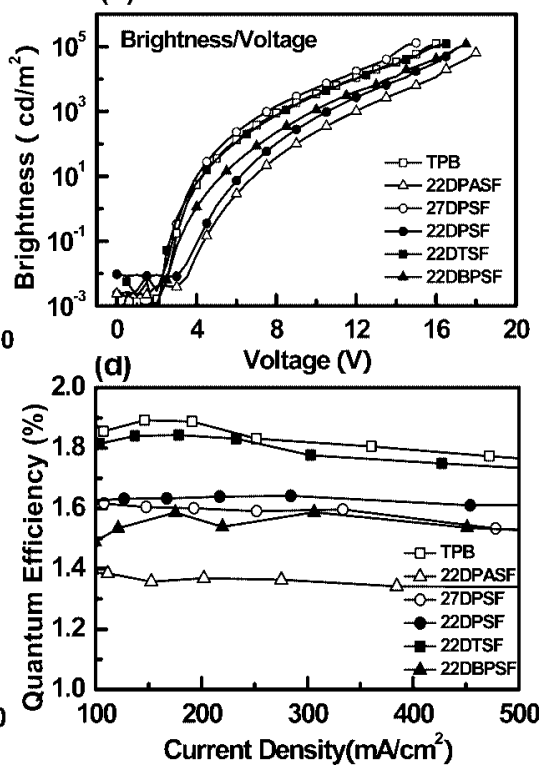

Figure 5. (a) EL spectrum of the device incorporating 22DPASF as the HTL, (b) brightness vs voltage characteristics, (c) current density vs voltage characteristics, and (d) external quantum efficiency vs current densities of various EL devices.

GDM, we extracted the charge transport parameters of 22DPASF and 27DPSF from detailed temperature- and field-dependent hole mobility measurements. The relatively high current density (ca. $5200 \mathrm{~mA} \mathrm{~cm}^{-1}$ ), impressive maximum brightness $\left(1.3 \times 10^{5} \mathrm{~cd} \mathrm{~m}^{-2}\right)$, and high external quantum efficiency $(1.8 \%)$ that we obtained suggest the feasibility of using such triaryldiamine compounds as HTLs in OLEDs.

Acknowledgment. This study was supported financially by the National Science Council of Taiwan.

CM702230E 